\title{
Current Psychosomatic Practice
}

\author{
Giovanni A. Fava ${ }^{a, d}$ Fiammetta Cosci ${ }^{b}$ Nicoletta Sonino ${ }^{c, d}$ \\ ${ }^{a}$ Department of Psychology, University of Bologna, Bologna, ${ }^{b}$ Department of Health Sciences, University of \\ Florence, Florence, and ' ${ }^{\mathrm{C}}$ Department of Statistical Sciences, University of Padova, Padova, Italy; ${ }^{\mathrm{d} D e p a r t m e n t}$ of \\ Psychiatry, University at Buffalo, Buffalo, N.Y., USA
}

\section{Key Words}

Psychosomatic medicine · Stress · Allostatic load ·

Depression · Anxiety · IIIness behavior · Patient-reported outcomes · Psychotherapy · Clinimetrics · Diagnostic Criteria for Psychosomatic Research

\begin{abstract}
Psychosomatic research has advanced over the past decades in dealing with complex biopsychosocial phenomena and may provide new effective modalities of patient care. Among psychosocial variables affecting individual vulnerability, course, and outcome of any medical disease, the role of chronic stress (allostatic load/overload) has emerged as a crucial factor. Assessment strategies include the Diagnostic Criteria for Psychosomatic Research. They are presented here in an updated version based on insights derived from studies carried out so far and encompass allostatic overload, type A behavior, alexithymia, the spectrum of maladaptive illness behavior, demoralization, irritable mood, and somatic symptoms secondary to a psychiatric disorder. Macroanalysis is a helpful tool for identifying the relationships between biological and psychosocial variables and the individual targets for medical intervention. The personalized and holistic approach to the patient includes integration of medical and psychological therapies in all phases of illness. In this respect, the development of a new psychotherapeu-
\end{abstract}

tic modality, Well-Being Therapy, seems to be promising. The growth of subspecialties, such as psychooncology and psychodermatology, drives towards the multidisciplinary organization of health care to overcome artificial boundaries. There have been major transformations in health care needs in the past decades. From psychosomatic medicine, a land of innovative hypotheses and trends, many indications for changes in the current practice of medicine are now at hand. The aim of this critical review is to outline current and potential clinical applications of psychosomatic methods.

(c) 2016 S. Karger AG, Basel

\section{Introduction}

Psychosomatic medicine is a wide interdisciplinary field that is concerned with the interaction of biological, psychological, and social factors in regulating the balance between health and disease [1-4]. It provides a conceptual framework for:

1 scientific investigations on the role of psychosocial factors affecting individual vulnerability, course, and outcome of any type of medical disease;

2 the personalized and holistic approach to the patient, adding psychosocial assessment to the standard medical examination;

\section{KARGER}

(c) 2016 S. Karger AG, Basel

E-Mail karger@karger.com

www.karger.com/pps
Giovanni A. Fava, MD

Department of Psychology, University of Bologna

viale Berti Pichat, 5

IT-40127 Bologna (Italy)

E-Mail giovanniandrea.fava@unibo.it 


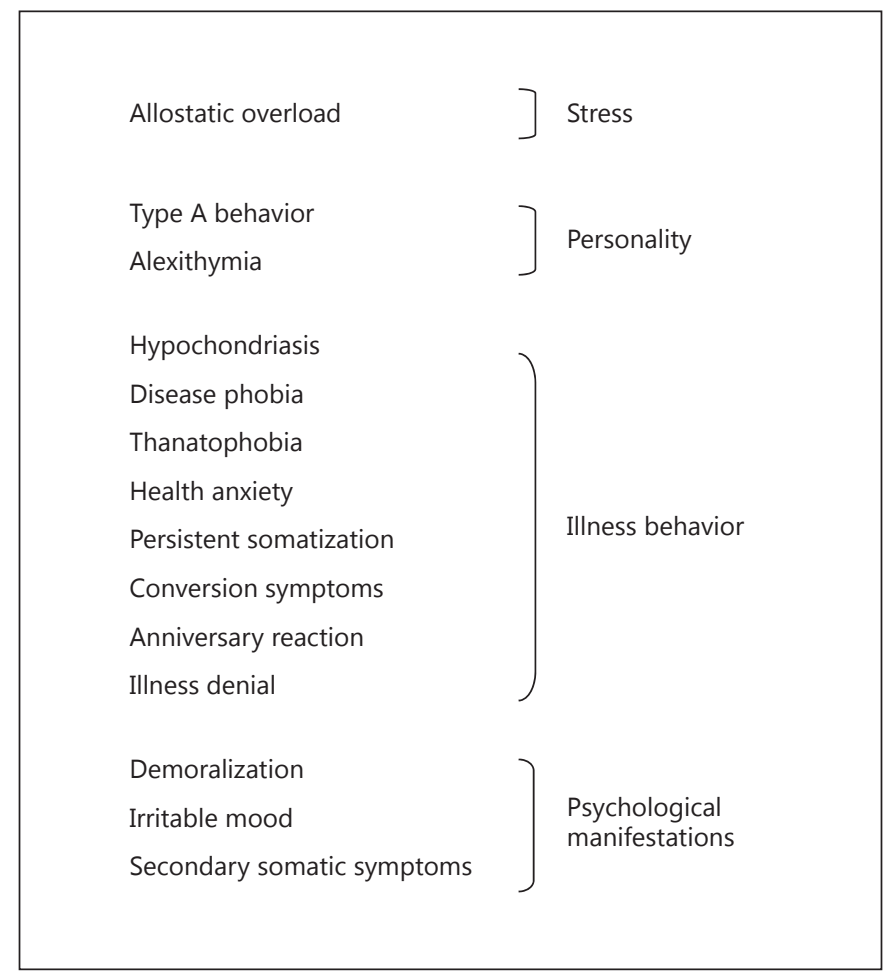

Fig. 1. DCPR, revised version.

3 the integration of psychological and psychiatric therapies in the prevention, treatment, and rehabilitation of medical disease, and

4 multidisciplinary organization of health care that overcomes the artificial boundaries of traditional medical specialties.

Psychosomatic research, in the past decades, has resulted in an impressive body of knowledge, with contributions published in all major medical journals and in specifically dedicated journals such as Psychosomatic Medicine, Psychosomatics, Psychotherapy and Psychosomatics, and the Journal of Psychosomatic Research. Its application has generated a number of subdisciplines: psychooncology, psychonephrology, psychoneuroendocrinology, psychoneurogastroenterology, behavioral cardiology, psychoimmunology, psychodermatology, and others, which in turn have developed clinical services, scientific societies, and medical journals [5].

In this context, the Diagnostic Criteria for Psychosomatic Research (DCPR) have helped to translate psychosocial variables that derived from psychosomatic research into operational tools. The DCPR, introduced in 1995 [6], were tested in various clinical settings. Their value in the psychosomatic assessment, regardless of the 'organic' or 'functional' nature of the illness, has been largely documented [7-9].

The aim of this critical review is to outline current and potential clinical applications of psychosomatic methods. It includes contributions, particularly from review articles, that are most relevant to clinical practice. For the first time, the DCPR are reported in a revised version based on insights derived from their use in a large number of patients and settings $[7,8]$. This version includes the diagnostic criteria for two additional syndromes, allostatic overload and hypochondriasis. The DCPR will be described in relation to the clinical domains to which they pertain (fig. 1).

Issues concerned with disciplines related to psychosomatic medicine, such as behavioral medicine [10], health psychology [11], and mind-body medicine $[12,13]$, are not included in this paper.

\section{Psychosocial Factors and Individual Vulnerability}

A number of factors have been implied to modulate individual vulnerability to disease.

\section{Life Events and Allostatic Load}

The role of early developmental factors in the susceptibility to disease has been a frequent object of psychosomatic investigation [14]. Using animal models, events such as premature separation from the mother have consistently resulted in pathophysiological modifications, mainly an increased HPA axis activation [15]. They may render the human individual more vulnerable to the effects of stress later in life. There has been also considerable interest in the association of physical and sexual abuse in childhood with medical disorders later in life, yet the evidence currently available does not allow any firm conclusion [14]. Children exposed to maltreatment showed changes (smaller volume of the prefrontal cortex, increased activation of the HPA axis, and elevation in levels of inflammation) that persisted in adult age [16].

That stressful life events may be followed by ill health has been a common clinical observation. The introduction of structured methods of data collection and control groups has allowed substantiation of the link between life events in the year preceding the onset of symptoms and a number of medical disorders, encompassing endocrine, cardiovascular, respiratory, gastrointestinal, autoimmune, skin, and neoplastic disease [17-19]. Indeed, within a multifactorial frame of reference, stressful life events may affect the regulatory mechanisms of neuroen- 
Table 1. Allostatic overload: revised version of the DCPR (criteria A and B are required)

\begin{tabular}{|c|c|}
\hline Criterion A & $\begin{array}{l}\text { The presence of a current identifiable source of distress in the form of recent life events and/ } \\
\text { or chronic stress; the stressor is judged to tax or exceed the individual coping skills when its } \\
\text { full nature and full circumstances are evaluated }\end{array}$ \\
\hline Criterion B & $\begin{array}{l}\text { The stressor is associated with } 1 \text { or more of the following } 3 \text { features, which have occurred } \\
\text { within } 6 \text { months after the onset of the stressor: } \\
\text { (1) At least } 2 \text { of the following symptoms: difficulty falling asleep, restless sleep, early } \\
\text { morning awakening, lack of energy, dizziness, generalized anxiety, irritability, sadness, } \\
\text { demoralization } \\
\text { (2) Significant impairment in social or occupational functioning } \\
\text { (3) Significant impairment in environmental mastery (feeling overwhelmed by the demands } \\
\text { of everyday life) }\end{array}$ \\
\hline
\end{tabular}

docrine-immune functions in a number of ways [17-19]. Stress at large may result in responses mediated by a variety of neurotransmitters, proinflammatory cytokines, and hormones [20,21], both in the brain and the periphery. In turn, chronic inflammation may play a key role in the pathogenesis of major disorders such as diabetes, cardiovascular disease, and cancer [22, 23].

On the other hand, subtle and long-standing life situations should not too readily be dismissed as minor and negligible, since chronic, daily life stresses may be experienced by the individual as taxing or exceeding his/her coping skills. McEwen [15] proposed a formulation of the relationship between stress and the processes leading to disease based on the concept of allostasis, the ability of the organism to achieve stability through change. In this view, allostatic load reflects the cumulative effects of stressful experiences in daily life. When the cost of chronic exposure to fluctuating and heightened neural or neuroendocrine responses exceeds the coping resources of an individual, allostatic overload ensues. Allostatic overload can be assessed by specific clinimetric criteria [24] that underwent validation [25-28]. They are now included in the revised version of the DCPR (table 1).

Biological parameters of allostatic load have been linked to cognitive and physical functioning and mortality $[15,29]$. Regions of the prefrontal cortex, hippocampus, and amygdala are particularly affected [30].

\section{Health Attitudes and Behavior}

Behaviors relevant to health mainly relate to physical activity, diet, sleep, smoking, drinking, and drug consumption. These behavioral factors are interrelated and can have a synergistic effect on morbidity and mortality $[31,32]$. However, changing the unhealthy behavior of an individual is always difficult. For instance, about $75 \%$ of patients with cardiovascular diseases were unable to change their bad habits despite the fact that they were informed about the risk factors [33]. Similarly, knowledge about the risks associated with certain health-damaging behaviors is not necessarily associated with their avoidance. A survey on young adults in 8 countries throughout Europe [34] showed that those who engaged more in drinking and smoking were just as much aware of the negative consequences of these health-damaging behaviors as people who did not engage in such behaviors. In contrast, beliefs about the positive effects of health-protective behaviors were strongly associated with their practice [34].

\section{Social Support}

The complex interplay among environmental, social, familial, psychological, and physiological processes is likely to become embodied in the brain to influence health throughout life [35]. Dimensions of social relationships such as social network composition, social support, frequency of social interactions, and the experience of loneliness and isolation have long been linked to aspects of physical and mental health [35]. In this line, prospective population studies have substantiated the role of social support in relation to mortality, psychiatric and physical morbidity, recovery, and adjustment to chronic disease [36]. Interventions designed to improve the social environment and interpersonal relationships have been successful in facilitating psychosocial adjustment to medical disorders [36].

\section{Psychological Well-Being}

Several studies have suggested that positive affect plays a buffering role in coping with stress and has a favorable impact on disease course $[37,38]$. In recent years, there has been increasing interest in the concept of euthymia, a state characterized by psychological flexibility, resilience 
Table 2. Type A behavior: revised version of the DCPR (criterion A is required)

\begin{tabular}{l}
\hline Criterion A \\
At least 5 of the 9 following characteristics should be present: \\
(1) Excessive degree of involvement in work and other activities subject to deadlines \\
(2) Steady and pervasive sense of urgency \\
(3) Display of motor-expressive features (rapid and explosive speech, abrupt body \\
movements, tensing of facial muscles, hand gestures) indicating a sense of being under \\
pressure of time \\
(4) Hostility and cynicism \\
(5) Irritability \\
(6) Tendency to speed up physical activities \\
(7) Tendency to speed up mental activities \\
(8) High desire for achievement and recognition \\
(9) High competitiveness
\end{tabular}

Table 3. Alexithymia: revised version of the DCPR (criterion A is required)

Criterion A least 3 of the following 6 characteristics should be present:
(1) Inability to use appropriate words to describe emotions
(2) Tendency to describe details instead of feelings (e.g. circumstances surrounding an event
rather than the feelings)
(3) Lack of a rich fantasy life
(4) Thought content associated more with external events rather than fantasy or emotions
(5) Unawareness of common somatic reactions that accompany the experience of a variety
of feelings
(6) Occasional but violent and often inappropriate outbursts of affective behavior

to stress, and lack of affective disturbances [39]. Preclinical evidence suggests that conditions of persistent stress may elicit a pattern of conserved transcriptional response to adversity, in which there is an increased expression of proinflammatory genes and a concurrent decreased expression of type 1 interferon innate antiviral response [40]. Such a pattern has been implicated in the pathophysiology of cancer and cardiovascular disease [22, 41]. Frederickson et al. [42] showed that individuals with high psychological well-being presented reduced gene expression of conserved transcriptional response to adversity, suggesting a potential protective role of psychological well-being in a number of medical disorders.

\section{Spirituality}

Religiosity and spirituality (broadly defined as any feelings, thoughts, experiences, and behaviors that arise from the search for the 'sacred') have been a matter of growing interest in epidemiological research [43]. Religiosity appeared to have a favorable effect on survival that is independent from behavioral factors, negative affect, and degree of social support $[43,44]$.

\section{Personality}

The notion that personality variables can affect vulnerability to specific diseases was prevalent in the first phase of the development of psychosomatic medicine (1930-1960) and was particularly influenced by psychoanalytic investigators who believed that personality profiles would underlay specific 'psychosomatic diseases'. This hypothesis was not supported by subsequent research [1]. Two personality constructs that can potentially affect general vulnerability to disease, type A behavior (table 2) and alexithymia (table 3), have attracted considerable attention, but their relationship with health issues is still controversial [45]. Type A behavior is derived from the 'specific emotional complex' observed in patients with heart conditions in the late 1950s [46] and has been recognized in $36.1 \%$ of subjects at risk of coronary heart disease and in $10.8 \%$ of patients with noncardiac diseases [47]. Alexithymia appears to be linked to increased risk and worsened outcome of medical conditions such as cardiovascular diseases, gastrointestinal disorders, cancer, and altered immune response to stress [48-51].
16

Psychother Psychosom 2017;86:13-30 DOI: $10.1159 / 000448856$
Fava/Cosci/Sonino 
Personality variables may deeply affect how a patient views illness, what it means to him/her, and his/her interactions with others, including medical staff. The neurobiology of personality features, such as reward dependence and novelty seeking [52], alexithymia [53], and type A behavior [54], provides valuable pathophysiological insights into the tendency to develop symptoms and abnormal illness behavior in the setting of medical disease.

\section{Implications for Clinical Practice}

Assessment of psychosocial factors potentially influencing individual vulnerability to illness is often omitted by the primary care physician or the medical specialist [4]. This is the result of a reductionist approach that has deeply influenced medicine $[4,11,12,17,55,56]$.

Psychosocial variables affecting illness vulnerability may encompass:

1 a temporal relationship between life events and symptom onset or relapse;

2 the presence of grief reactions, including the loss of a body part or bodily function;

3 the perception by a person of an environment as exceeding his/her resources (i.e. allostatic load/overload). Often patients deny a relationship between their allostatic load and symptomatology, since they are unaware of the latency between stress accumulation and symptom onset ('I had bowel symptoms yesterday, which was an easy day at work, and not the previous days, which were awful'). Symptom worsening during weekends and vacation time is a common manifestation of this latency [57];

4 interpersonal relationships providing a buffering role for stress, and

5 psychological assets and well-being.

This type of information may be crucial in managing patients with unexplained somatic symptoms [58], with difficult patient-doctor relationships [59], or with borderline/mild hormone abnormalities (e.g. slightly elevated prolactin levels) [60]. It may be obtained by expert interviewing and/or self-rating inventories and/or techniques of self-observation (i.e. self-monitoring of daily activities and recording of the observed experiences in a diary) [61]. Psychosomatic medicine has provided lasting contributions to improving history taking in medical settings [62].

\section{Psychosomatic Assessment and Individualized Care}

The unified concept of health and disease of Engel [55, 63] allowed illness to be viewed as the result of interacting mechanisms at the cellular, tissue, organismic, interpersonal, and environmental levels. Hinkle [64] in 1967 added human ecology as a core characterization of psychosomatic medicine, anticipating ecological issues such as the growing importance of environmental toxic factors and the social inequalities that affect health [65].

Tinetti and Fried [66] suggested that the aim of the treatment should be the attainment of individual goals and the identification of all modifiable biological and nonbiological factors and pointed out: 'A primary focus on disease, given the changed health needs of patients, inadvertently leads to under-treatment, overtreatment, or mistreatment' [66].

The psychosomatic evaluation includes important psychosocial variables according to clinimetric principles [67-73]. The term 'clinimetrics' was introduced by a supporter of the psychosomatic movement, Alvan R. Feinstein, in 1982, to indicate a domain concerned with indexes, rating scales, and other expressions that are used to describe or measure symptoms, physical signs, and other clinical phenomena [67]. The psychosomatic approach requires a comprehensive assessment, satisfactory patient-doctor interaction, and the application of individualized care $[5,61,74]$.

\section{Quality of Life and Patient-Reported Outcomes}

Psychosomatic medicine pioneered the self-rated evaluation of psychological status in medical conditions [61]. Rating scales such as the Symptom Check List 90 [75], the Hospital Anxiety and Depression Scale [76], and the Symptom Questionnaire [77] were extensively used in medical settings $[68,78]$. Evaluations of distress and wellbeing anticipated interest in quality of life assessments and patient-reported outcomes. While there is neither a precise nor an agreed definition of quality of life, research in this area seeks essentially two kinds of information: the functional status of the individual and the patient's appraisal of his/her own health. Indeed, the subjective perception of health status (e.g. lack of well-being, demoralization, difficulties fulfilling personal and family responsibilities) is as valid as that of the clinician in evaluating outcomes [79-81]. The recent emphasis on patient-reported outcomes, any report coming directly from patients about how they function or feel in relation to a health condition or its therapy $[82,83]$, is in line with the psychosomatic and clinimetric approach [84]. 
Table 4. Hypochondriasis: revised version of the DCPR (criteria A-D are required)

\begin{tabular}{ll}
\hline Criterion A & $\begin{array}{l}\text { Fears of having, or the idea of having, a serious disease based on misinterpretation of bodily } \\
\text { symptoms }\end{array}$ \\
Criterion B & $\begin{array}{l}\text { The preoccupations persist despite adequate medical evaluation and reassurance, with } \\
\text { opportunity for discussion and clarification }\end{array}$ \\
Criterion C & $\begin{array}{l}\text { The duration of the disturbance is at least } 6 \text { months } \\
\text { The preoccupations cause marked distress and/or impairment in social and occupational } \\
\text { Criterion D }\end{array}$ \\
\hline
\end{tabular}

Table 5. Disease phobia: revised version of the DCPR (criteria A-C are required)

\begin{tabular}{ll}
\hline Criterion A & $\begin{array}{l}\text { Persistent, unfounded fear of suffering from a specific disease (e.g. AIDS, cancer), with } \\
\text { doubts remaining despite adequate medical examination and reassurance }\end{array}$ \\
Criterion B & $\begin{array}{l}\text { Fears tend to manifest themselves in the form of attacks rather than in constant, chronic } \\
\text { worries as in hypochondriasis; panic attacks may be an associated feature }\end{array}$ \\
Criterion C & $\begin{array}{l}\text { The object of fear does not change with time, and the duration of symptoms exceeds } 6 \\
\text { months }\end{array}$
\end{tabular}

Table 6. Thanatophobia: revised version of the DCPR (criteria A-C are required)

\begin{tabular}{ll}
\hline Criterion A & $\begin{array}{l}\text { At least } 2 \text { attacks in the past } 6 \text { months of impending death and/or conviction of dying soon, } \\
\text { without being in a threatening situation or in real danger; adequate appraisal of the situation } \\
\text { and management to be followed (if any) has been provided by a physician, with an } \\
\text { opportunity for discussion and clarification }\end{array}$ \\
Criterion B & $\begin{array}{l}\text { Marked and persistent fear and avoidance of news that reminds of death (e.g. funerals, } \\
\text { obituary notices); exposure to these stimuli almost invariably provokes an immediate } \\
\text { anxiety response } \\
\text { Avoidance, anxious anticipation, and distress interfere markedly with the level of } \\
\text { functioning }\end{array}$ \\
\hline
\end{tabular}

\section{Illness Behavior}

Mechanic and Volkart [85] defined illness behavior as 'the ways in which given symptoms may be differentially perceived, evaluated, and acted (or not acted) upon by different kinds of persons'. Subsequently, Mechanic [86] provided the following specification: 'Illness behavior refers to the varying ways individuals respond to bodily indications, how they monitor internal states, define and interpret symptoms, make attributions, take remedial actions and utilize various sources of informal and formal care.' In the past decades, new lines of research have been concerned with illness perception, attendance at medical facilities, health-care-seeking behavior, and treatment adherence [87, 88].

The simple fact that, in the presence of certain physical symptoms, some persons immediately seek medical help while others wait a long time before consulting a physi- cian determines the likelihood of early recognition of a life-threatening disease and its prompt treatment and prognosis. Thus, illness behavior is a core characterization in psychosomatic medicine and provides an explanatory model for clinical phenomena that do not find room in customary taxonomy [88].

The clinical spectrum of illness behavior encompasses a number of syndromes (fig. 1), including hypochondriasis, which was omitted in the DSM-5 classification [89]. Retaining hypochondriasis (table 4) is important since specific psychotherapeutic strategies have been developed and validated in randomized controlled trials: they were targeted to address resistance to reassurance, the key characteristic of hypochondriasis which can be favorably modified [88].

Disease phobia (table 5) and thanatophobia (table 6) may be components of a hypocondriacal syndrome, yet
18

Psychother Psychosom 2017;86:13-30 DOI: $10.1159 / 000448856$
Fava/Cosci/Sonino 
Table 7. Health anxiety: revised version of the DCPR (criteria A and B are required)

Criterion A A generic worry about illness, concern about pain, and bodily preoccupations (tendency to amplify somatic sensations) of less than 6 months' duration

Criterion B Worries and fears readily respond to appropriate medical reassurance, even though new worries may ensue after some time

Table 8. Persistent somatization: revised version of the DCPR (criteria A and B are required)

Criterion A Functional medical syndromes (fibromyalgia, chronic fatigue, esophageal motility disorders, nonulcer dyspepsia, irritable bowel syndrome, atypical chest pain, overactive bladder) whose duration exceeds 6 months causing distress and/or seeking medical care and/or resulting in impaired quality of life

Criterion B Symptoms of autonomic arousal involving other organ systems (e.g. palpitations, tremor, flushing, sweating) and/or exaggerated side effects from medical therapy, indicating low threshold of pain sensation and/or high suggestibility

Table 9. Conversion symptoms: revised version of the DCPR (criteria A-C are required)

\begin{tabular}{ll}
\hline Criterion A & One or more symptoms or deficits affecting voluntary motor or sensory function \\
characterized by lack of anatomical or physiological plausibility and/or absence of expected \\
physical signs or laboratory findings and/or inconsistent clinical manifestations; if \\
autonomic arousal or persistent bodily symptoms are present, conversion symptoms should \\
be prominent and cause distress and/or seeking medical care and/or impaired quality of life \\
Appropriate medical evaluation uncovers no organic pathology to account for the physical \\
complaints \\
At least 2 of the following 4 characteristics should be present: \\
(1) Ambivalence in reporting of symptoms (e.g. the patient appears relaxed or unconcerned \\
as he/she describes distressing symptoms) \\
(2) Histrionic personality features (colorful and dramatic expressions, language and \\
appearance, demanding dependency, high suggestibility, rapid mood changes) \\
(3) Precipitation of symptoms by psychological stress (the patient is unaware of such \\
association) \\
(4) History of similar physical symptoms experienced by the patient, observed in someone \\
else, or wished on someone else
\end{tabular}

they may also occur independently. Disease phobia differs from hypochondriasis in three characteristics: (1) fears concern a specific disease and are unlikely to be shifted to another disease or organ system [88]; (2) fears tend to manifest themselves in attacks rather than in constant worries as in hypochondriasis [90], and (3) disease phobia often results in the avoidance of internal and external illness-related stimuli, while hypochondriasis usually involves reassurance-seeking or checking behaviors [91]. Disease phobia was found in 19\% of consultationliaison psychiatry patients [92, 93].

Health anxiety (table 7) is characterized by worries and attitudes concerning illness and pain that are less specific than in hypochondriasis and disease phobia and respond to medical reassurance. It frequently occurs (21-35\%) among consultation-liaison psychiatry patients $[92,93]$.

Persistent somatization (table 8) refers to patients in whom somatic symptoms have clustered, probably due to an enhanced general sensitivity to pain and discomfort [94]. For instance, findings of altered brain-gut interactions, inflammation, and visceral hypersensitivity shed new light on the pathophysiology of irritable bowel syndrome [95, 96], and advanced brain imaging methods make the distinction between 'functional' and 'organic' increasingly blurred [97]. Persistent somatization may be associated with a variety of medical disorders [8]. 
Table 10. Anniversary reaction: revised version of the DCPR (criteria A-C are required)

\begin{tabular}{ll}
\hline Criterion A & $\begin{array}{l}\text { Symptoms of autonomic arousal (e.g. palpitations, tremor, flushing, sweating) or functional } \\
\text { syndromes (e.g. irritable bowel syndrome, fibromyalgia, atypical chest pain) or conversion } \\
\text { symptoms causing distress and/or seeking medical care and/or impaired quality of life }\end{array}$ \\
Criterion B & $\begin{array}{l}\text { Appropriate medical evaluation uncovers no organic pathology to account for physical } \\
\text { symptoms }\end{array}$ \\
Criterion C & $\begin{array}{l}\text { Symptoms began when the patient reached the age, or on the occasion of the anniversary, } \\
\text { when a parent or very close family member developed a life-threatening illness and/or died; } \\
\text { the patient is unaware of such association }\end{array}$ \\
\hline
\end{tabular}

Table 11. Illness denial: revised version of the DCPR (criteria A and B are required)

Criterion A Persistent denial of having a physical disorder and needing treatment (e.g. lack of compliance, delayed seeking of medical attention for serious and persistent symptoms, counterphobic behavior) as a reaction to the symptoms, signs, diagnosis, or medical treatment of a physical illness

Criterion B The patient has been provided with an adequate appraisal of the medical situation and management (if any) to be followed, with opportunity for discussion and clarification

Conversion symptoms (table 9) were formulated according to the criteria of Engel [98]. In a sample of 1,498 patients from various medical settings [100], DCPR conversion symptoms [6] were found in $4.5 \%$ of subjects, while DSM-IV conversion disorder [99] was found in only $0.4 \%$. In the same study [100], anniversary reaction (table 10), which is a special form of somatization or conversion, had a prevalence of $3.6 \%$.

Illness denial (table 11) pertains to patients who do not acknowledge the presence or severity of their illness. DCPR illness denial was found in $9 \%$ of women with breast cancer [101] and in 5\% of subjects who underwent heart transplantation [102].

At variance with the DSM classification system, all the DCPR syndromes that connote the persistence of a maladaptive mode of experiencing, perceiving, evaluating, and responding to one's own health status require the fact that a doctor has provided an adequate appraisal of the situation and management to be followed (if any), with opportunity for discussion, negotiation, and clarification [103]. If a patient has not been provided with adequate information about his/her medical condition and management and develops overwhelming anxiety about his/ her health, is a psychiatric diagnosis warranted as the DSM suggests? Is the problem caused by the patient or by an inadequate patient-doctor interaction?

\section{Demoralization and Irritable Mood}

There is emerging awareness that psychological symptoms which do not reach the threshold of a psychiatric disorder may also affect quality of life and entail pathophysiological and therapeutic implications. The advantage of DCPR classification is that it departs from the dichotomy between organic and functional and from the misleading and dangerous assumption that if organic factors cannot be identified there must be psychological reasons which fully explain the somatic symptomatology. The psychosomatic literature provides an endless series of examples where psychological factors could only partially account for the unexplained medical disorder [88]. In turn, the presence of an established organic cause for a medical disorder does not exclude but indeed increases the likelihood of psychological distress [4]. In this respect, two syndromes in the revised DCPR, demoralization and irritable mood, deserve to be mentioned.

The original DCPR definition of demoralization integrated the demoralization syndrome of Frank [104] and the giving up-given up complex of Schmale and Engel [105]. Demoralization and major depression can be differentiated on clinical grounds; they may occur together or independently, and major depression does not necessarily involve demoralization [106]. DCPR studies on demoralization reported very low prevalence in healthy participants (not higher than 2-5\%) and a high prevalence in the medically ill (about 30\%) [106]. Table 12 shows the 
Table 12. Demoralization: revised version of the DCPR (criteria A and B are required; criterion C is a specifier for the presence of hopelessness)

$\begin{array}{ll}\text { Criterion A } & \begin{array}{l}\text { A feeling state characterized by the perception of being unable to cope with some pressing } \\ \text { problems and/or of lack of adequate support from others (helplessness); the individual } \\ \text { maintains the capacity to react }\end{array} \\ \text { Criterion B } & \begin{array}{l}\text { The feeling state is prolonged and generalized (duration of at least 1 month) } \\ \text { A feeling state characterized by the consciousness of having failed to meet expectations } \\ \text { associated with the conviction that there are no solutions for current problems and } \\ \text { difficulties (hopelessness) }\end{array}\end{array}$

Table 13. Irritable mood: revised version of the DCPR (criteria A and B are required)

\begin{tabular}{ll}
\hline Criterion A & $\begin{array}{l}\text { A feeling state characterized by irritability which may be experienced as brief episodes (in } \\
\text { particular circumstances) or may be prolonged and generalized; it requires an increased } \\
\text { effort of control over temper or results in irascible verbal or behavioral outbursts }\end{array}$ \\
Criterion B & $\begin{array}{l}\text { The experience of irritability is always unpleasant, and overt manifestations lack the } \\
\text { cathartic effect of justified outbursts of anger }\end{array}$
\end{tabular}

revised DCPR criteria for demoralization and its two different expressions: helplessness (the individual maintains the capacity to react but lacks adequate support) and hopelessness (when the individual feels he/she alone is responsible for the situation and there is nothing he/she or anyone else can do to overcome the problem) [107]. Hopelessness/giving up is more likely to be linked to depressive illness and may provide a severity connotation to the diagnosis of major depressive disorder. Both hopelessness and helplessness have been found to involve the serotonergic and noradrenergic systems [108].

Table 13 shows the revised DCPR criteria for irritable mood. Irritability may be part of psychiatric syndromes; it is always unpleasant for the individual, and its overt manifestation lacks a cathartic effect [109]. Several studies found a significant impact of irritable mood on the course of medical disorders as well as on the adoption of unhealthy lifestyles [110-114]. Prevalence rates of DCPR irritable mood of about $10-15 \%$ were found in medical settings, including patients with myocardial infarction, heart transplantation, functional gastrointestinal disturbances, cancer, and skin diseases [8] and up to $46 \%$ in patients with endocrine disorders [115].

\section{Psychiatric Disorders}

Psychiatric illness appears to be strongly associated with physical diseases: mental disorders increase the risk for communicable and noncommunicable diseases; many health conditions increase the risk for mental disturbanc- es; comorbidity complicates recognition and treatment of medical disorders [116].

There is evidence that psychiatric disturbances in the course of medical disease are substantially different from those that can be found in psychiatric settings in terms of clinical characteristics, response to treatment, and prognosis $[116,117]$. At times, mood and anxiety disturbances precede the onset of symptoms of a medical condition [117]. The potential relationship between medical disorders and psychiatric symptoms ranges from a purely coincidental occurrence to a direct causal role of organic factors. The latter may be subsumed under the rubric of symptomatic affective disorder whose key feature is the resolution of psychiatric disturbances upon specific treatment of the organic condition [118].

As to depression, to reach a correct diagnosis in primary care is a difficult task, and a meta-analysis [119] indicated that there are more false positives than either missed or correctly identified cases. Major depression has emerged as an extremely important source of comorbidity in medical disorders. In particular:

1 Depression may increase susceptibility to medical illness. Depression is characterized by a sustained inflammatory state, and increased concentrations of inflammatory markers might have a role in mediating the risk for cardiovascular and neoplastic disease [22, $41,120]$. It has been suggested to also be a marker of disease severity. For example, in pituitary-dependent Cushing's disease, the presence of depression was as- 
Table 14. Somatic symptoms secondary to a psychiatric disorder: revised version of the DCPR (criteria A-C are required)

$\begin{array}{ll}\text { Criterion A } & \begin{array}{l}\text { Somatic symptoms that cause distress and/or seeking medical care and/or impaired quality } \\ \text { of life } \\ \text { Appropriate medical evaluation uncovers no organic pathology to account for the physical } \\ \text { Criterion B }\end{array} \\ \text { Criterion C } & \begin{array}{l}\text { A psychiatric disorder (which includes somatic symptoms within its manifestations) } \\ \text { preceded the onset of somatic symptoms (e.g. panic disorder preceding cardiac symptoms) }\end{array}\end{array}$

sociated with the severity of the clinical presentation [121] and entailed prognostic value [122].

2 Medically unexplained symptoms are extremely common in medical practice. Their association with depression has been consistent, regardless of the design of the study $[94,123]$. Depressed patients tend to have more somatic symptoms than nondepressed individuals $[94,123]$.

3 The presence of depressive symptoms in association with chronic medical illness was found to affect quality of life and social functioning and lead to increased health care utilization [123].

4 Depression was found to have an impact on compliance [124]. Many cases of 'suicide by default' in the medical population may mask a major depressive disorder [125]. Examples include diabetic patients who stop taking insulin, those who resume strenuous work after myocardial infarction, and those who withdraw from chronic hemodialysis [125].

5 Depression may be a risk factor for nonsuicide mortality [123], particularly in the elderly [126].

The relationship between anxiety disorders and medical illness has also been found to entail important clinical implications [127-129]. The revised DCPR diagnosis of somatic symptoms secondary to a psychiatric disorder (table 14) acknowledges their hierarchical relationship to psychiatric disorders, particularly mood and anxiety disturbances (e.g. symptoms of autonomic arousal may frequently be a consequence of anxiety) $[130,131]$. With the DCPR syndrome of somatic symptoms secondary to a psychiatric disorder the physician formulates the hypothesis that the bulk of somatic symptomatology may remit upon the remission of the psychiatric disorder (e.g. successful treatment of anxiety may entail a decrease or disappearance of its somatic manifestations) [128].

As discussed in detail elsewhere [88, 132], the DSM-5 diagnosis of 'somatic symptom and related disorders' as well as 'adjustment disorders' have limited clinical utility in psychosomatic medicine.

\section{Implications for Clinical Practice}

Emmelkamp et al. [133] introduced the concept of macroanalysis (a relationship between co-occurring syndromes and problems is established on the basis of where treatment should start first). Macroanalysis begins from the assumption that in most cases there are functional relationships among different problem areas and that the targets of treatment may vary during the course of disturbances. The hierarchical organization that is chosen may depend on a variety of contingent factors (e.g. urgency, availability of treatment choices) that also include the patient's preferences and priorities. Macroanalysis is a tool for the therapist that can also be used to inform the patient about the relationship between different problem areas and induce motivation to change. Macroanalysis should be supplemented by microanalysis: a detailed analysis of the onset and course of the complaints and the circumstances that worsen symptoms [61].

A comprehensive assessment of psychosocial aspects of medical disease cannot be equated to a standard psychiatric evaluation [61] and may be particularly suitable in the case of the following:

1 Medically unexplained symptoms. Patients with medically unexplained symptoms suffer from patterns of persistent bodily complaints that lack an underlying physical pathology despite intensive diagnostic efforts. Fourteen common physical symptoms are responsible for almost half of all primary care visits [58, 134], but only $10-15 \%$ are found to be caused by an organic illness over a 1-year period. Prevalence rates between 16 and $32 \%$ have been reported [135]. Medically unexplained symptoms cause costs in health care that are comparable to mental health problems like depression or anxiety [135]. These patients often spend more days in bed than patients with severe major medical disorders [136].

2 Partial response to treatment/incomplete recovery. Quality of life may often be compromised even when the patient is apparently doing well. An example may
Fava/Cosci/Sonino 
Table 15. Nonspecific therapeutic ingredients

Full availability of the therapist for specific times

Opportunity for the patient to ventilate thoughts and feelings

An emotionally charged, confiding relationship with a helping person

A plausible explanation of the symptoms

The active participation of patient and therapist in a ritual or procedure that is believed

by both to be the means of restoring patient health be provided by patients successfully treated for endocrine disorders and their incomplete recovery in terms of amelioration of quality of life [137]. Research on quality of life has emphasized the discrepancies in health perceptions between patients, their companions, and their treating physicians [80].

3 Psychiatric complications in medical illness. A timely identification is warranted in medical settings of psychiatric disturbances which need specific treatments. Kornfeld [138] illustrated that the recognition of psychiatric complications, such as delirium in coronary care units, yielded some changes in medical care and organization. As important is the awareness of psychiatric side effects caused by medical drugs [139].

4 Maladaptive illness behavior. Several manifestations of illness behavior (from hypochondriasis to illness denial) may hinder the prevention and treatment of medical disorders $[87,88]$, as outlined above.

\section{Integration of Psychological Care into Medical Treatment}

The main levels of psychosomatic intervention are as follows: prevention strategies and health behavior modifications, type of approach to patient care, and specific psychotherapeutic and psychopharmacological management in the setting of medical disease.

\section{Health Behavior Modifications}

Switching the general population to healthy lifestyles would be a major source of prevention for most prevalent conditions such as diabetes, obesity, and cardiovascular illness [140-143]. Addressing the origins of disparities in physical and mental health care early in life may produce greater effects than attempting to modify health-related behaviors later [144]. The exponential spending on preventive medication justified by the potential long-term benefits to a small segment of the population has been challenged [145], whereas the benefits of modifying life- style by population-based measures are increasingly demonstrated [145-147]. However, at present almost all of health care spending is directed at the traditional biomedically oriented care.

\section{General Psychosomatic Approach}

Levels of intervention may range from reassurance and effective communication (whether in primary care or in medical specialties) to the integration of specific psychotherapeutic and psychopharmacological treatments within the medical management [148]. Research on psychotherapy [4] has disclosed common therapeutic ingredients that may be specific or nonspecific [4] and are relevant to any physician-patient relationship (table 15). There is experimental evidence, mainly from studies concerned with placebo, that the mesolimbic dopaminergic system is activated when a patient expects clinical improvement [108]. These findings shed new light on classic psychosomatic studies exploring patient-doctor interactions $[149,150]$. Expectations, preferences, motivation, and quality of patient-doctor interactions are examples of variables that may affect treatment outcomes [151-153]. In a pioneer study [154], a small amount of individual attention and education (about what to expect during the postsurgical period) by the anesthetist resulted in a significantly lower requirement of postsurgery analgesia and a shorter hospital stay compared to a control group submitted to usual postsurgical care. When these nonspecific therapeutic ingredients are missing or the patient displays a counterproductive behavior, drugs are unlikely to be superior to placebo [151-153, 155, 156].

\section{Psychotherapeutic Interventions}

Different psychotherapeutic techniques (psychoeducational interventions, stress management procedures, cognitive-behavioral therapy, brief dynamic therapy, family therapy, and group interventions) have been applied to medical patients in controlled investigations $[147,157-160]$. Areas that have been extensively explored are cardiovascular [120, 161-165], gastrointestinal [166], 
pulmonary [167], neurological disorders [168], chronic pain $[169,170]$, diabetes [171, 172], HIV/AIDS [173, 174], and cancer [175-177]. These interventions may improve lifestyle and self-management, coping, quality of life, distress (especially depression and anxiety), course of physical illness, treatment adherence, and reduction in utilization of medical services [157-177]. Dealing with the psychological distress of family caregivers is another important area of action [178].

For many years, abnormal illness behavior has been viewed mainly as an expression of personality predisposition and considered to be refractory to treatment by psychotherapeutic methods, but several controlled studies indicated that hypochondriasis is a treatable condition by the use of simple cognitive strategies [160].

Another emerging area of intervention is concerned with strategies increasing psychological well-being in all phases of medical illness [179-181], from prevention (decreased well-being has been associated with unhealthy behaviors) $[182,183]$ to rehabilitation (the process of rehabilitation requires the promotion of well-being and changes in lifestyle) [184]. Increasing well-being by WellBeing Therapy $[179,180]$ may contribute to improving health attitudes and behavior, either in combination with other therapeutic strategies or as a first-line approach.

\section{Psychopharmacology}

Psychotropic drugs in the setting of medical disease are often employed for purposes other than psychiatric disorders, and most prescriptions are written by primary practitioners and nonpsychiatric physicians. There has been a very rapid increase in the prescription of antidepressant drugs $[185,186]$, whereas the use of benzodiazepines has been relatively stable [187-189].

McEwen and Gianaros [30] remark that sleeping pills, anxiolytics, and antidepressants are employed to counteract manifestations of allostatic overload, but these agents have side effects and interactions that may be detrimental in the long term and do not entail a solution to the problems for which they are used. Any type of psychotropic drug treatment, particularly after long-term use, may increase the risk of experiencing additional psychopathology that does not necessarily subside with discontinuation of the drug and may modify the responsiveness to subsequent treatments [190, 191], leading to iatrogenic comorbidity $[139,192,193]$. While the judicious use of psychotropic drugs in the medically ill may reduce stress, promote daytime functioning, improve mood, and assist in sleep induction [194], their prolonged utilization is likely to cause problems, particularly in the case of se- lective serotonin reuptake inhibitors and serotonin noradrenaline reuptake inhibitors [191, 195]. A psychosomatic approach to psychotropic drug prescription thus applies, on an individual basis, to a careful balance between potential benefits and adverse effects [196].

\section{Implications for Clinical Practice}

Psychosomatic medicine may have a sobering effect on inappropriate prescriptions of psychotropic drugs in medical practice, with particular reference to antidepressants. The basic message sold to the physicians by pharmaceutical propaganda is that a better medical outcome could be obtained by treating depression, even in its milder forms, with readily available medications. Depression, in view of its clinical implications in the prognosis of medical disorders regardless of its actual severity, has been equated to 'bad cholesterol' and the use of antidepressant drugs to statins, which should not be refused to anyone as a preventive or treatment measure - well beyond their original indications [197]. While antidepressant drugs were found to be effective for treating major depression in the setting of medical disease [198, 199], their actions on improving medical outcomes have not been demonstrated $[200,201]$ and may rather involve side effects, interactions, and the likelihood of developing iatrogenic comorbidity [118, 190, 197, 202].

The use of macroanalysis in medical settings may provide the ground for incorporating psychosocial strategies in specific clinical situations:

1 the presence of psychological disturbances (e.g. demoralization, irritable mood) or of psychiatric illness (e.g. major depression, panic disorder);

2 refractoriness to lifestyle modifications guided by primary care or other nonpsychiatric physicians;

3 the presence of abnormal illness behavior (from hypochondriasis to illness denial) interfering with treatment or leading to frequent health care utilization, and 4 impaired quality of life and functioning not entirely justified by the medical condition.

\section{Multidisciplinary Care}

There have been major transformations in health care needs $[66,203,204]$. The traditional medical specialties, based mostly on organ systems (e.g. cardiology, gastroenterology), appear to be more and more inadequate in dealing with symptoms and problems which cut across organ system subdivisions and require a comprehensive approach. There are several examples around 
the world of multidisciplinary care guided by psychosomatic principles.

\section{Psychosomatic Inpatient Units}

Psychosomatic inpatient units are available mainly in Germany [205, 206], Japan [207, 208], and China [209]. The characteristics of the units vary according to the type of health system. Their aims are to provide joint medical and psychological care, which would not be possible in traditional facilities, for the prevention and treatment of chronic illness and job-related disturbances (such as burnout) [205].

\section{Consultation-Liaison Psychiatry}

Consultation-liaison psychiatry is a widespread modality for providing consultation in the general hospital $[210,211]$. It is mostly geared to treat the psychiatric complications of medical illness in adults during hospitalization. Specific geriatric and pediatric psychiatric consultation services are also available $[211,212]$. The existing literature indicates that the goals of consultation-liaison psychiatry (reducing the length of hospitalization and utilization of laboratory tests, providing an input on patient management, and improving social functioning after discharge) can be met, even though results considerably differ across studies [210, 213, 214]. Developments of consultation-liaison psychiatry are hindered by its modalities of assessment and treatment that follow a reductionist (psychiatric) paradigm, missing psychosocial perspectives and correlates that may affect the response to medical treatments $[215,216]$.

\section{Medical Consultation Services within the Mental Health System}

Medical comorbidity in psychiatric patients often goes undetected. Medical disorders may cause or exacerbate psychiatric disturbances [117, 217, 218]. Psychiatrists tend to miss the correct medical diagnosis because they may fail to think of nonpsychiatric reasons for their patients' complaints or may not have adequate instruments for detecting medical disorders $[117,217]$. However, specific medical consultation services (e.g. internal medicine, endocrinology) within the mental health system have been insufficiently endorsed [219].

\section{Multidisciplinary Services}

Multidisciplinary services have been developed within specialties and subspecialties such as oncology, cardiology, dermatology, gynecology, nephrology, gastroenterology, organ transplantation, and endocrinology [219-

Psychosomatic Practice
222]. Such services may be operated by various specialists (group approaches) or by a single specialist with a multidisciplinary background. These services address complaints that fall between disciplines and require a psychosomatic approach. In the UK, the establishment of centers within the National Health System for providing psychotherapy to patients with anxiety and depressive disorders [223] offers an example of the integration of treatments.

\section{Implications for Clinical Practice}

In health care, the product is clearly health, and the patient is one of the producers, not just a customer [224]. As a result, 'optimally efficient health production depends on a general shift of patients from their traditional roles as passive or adversarial consumers, to become producers of health jointly with their health professionals' [224].

The partnership paradigm includes both collaborative care, a patient-physician relationship in which physicians and patients make health decisions together [225], and self-management, a plan that provides patients with problem-solving skills to enhance their self-efficacy [226].

As Kroenke [227] argued, neither chronic medical nor psychiatric disorders can be managed adequately in the current environment of general practice, where the typical patient must be seen in 10-15 min or less. It is idealistic to pursue shared decision and self-management when the time for interaction is so minimal.

\section{Conclusions}

The need to include consideration of function in daily life, productivity, performance of social roles, intellectual capacity, emotional stability, and well-being has emerged as a crucial part of clinical investigation and patient care. Such awareness is far from being translated into operational steps in clinical practice, and the traditional outdated way of dealing with health problems still prevails. As Ioannidis [228] points out, influential randomized trials are generally done by and for the benefit of the industry, guidelines serve vested interests, and national and federal research funds are unable to address basic clinical questions. Even though 'personalized medicine', referred to as genomics-based knowledge, has promised to approach each patient as the biological individual he/she is, the practical applications have still a long way to go, and neglect of psychological, behavioral, and social features may actually lead to a 'depersonalized' medicine [229]. 
From psychosomatic medicine, many indications for change are now at hand and could lead other medical disciplines to an overdue reappraisal of evidence-based medicine, whose model clashes with clinical reality and current health care needs.

\section{Disclosure Statement}

The authors have no conflicts of interest to declare.

\section{References}

1 Lipowski ZJ: Psychosomatic medicine: past and present. Can J Psychiatry 1986;31:2-21.

2 Fava GA, Sonino N: Psychosomatic medicine: emerging trends and perspectives. Psychother Psychosom 2000;69:184-197.

3 Fava GA, Sonino N: The clinical domains of psychosomatic medicine. J Clin Psychiatry 2005;66:849-858.

4 Fava GA, Sonino N: Psychosomatic medicine. Int J Clin Practice 2010;64:1155-1161.

5 Wise TN: Psychosomatics: past, present and future. Psychother Psychosom 2014;83:6569.

6 Fava GA, Freyberger HJ, Bech P, Christodoulou G, Sensky T, Theorell T, Wise TN: Diagnostic criteria for use in psychosomatic research. Psychother Psychosom 1995;63:1-8.

7 Porcelli P, Sonino N (eds): Psychological Factors Affecting Medical Conditions. Basel, Karger, 2007.

8 Porcelli P, Guidi J: The clinical utility of the Diagnostic Criteria for Psychosomatic Research: a review of studies. Psychother Psychosom 2015;84:265-272.

9 Altamura M, Porcelli P, Balzotti A, Massaro $\mathrm{CR}$, Bellomo A: Influence of DCPR syndromes in the psychosocial functioning of patients with major depressive and bipolar disorders. Psychother Psychosom 2015;84:387388.

10 Miller NE: Behavioral medicine: symbiosis between laboratory and clinic. Annu Rev Psychol 1983;34:1-31.

11 Andrasik F, Goodie JL, Peterson AL: Biopsychosocial Assessment in Clinical Health Psychology. New York, Guilford Press, 2015.

12 Gordon JS: Manifesto for a New Medicine. Reading, Addison-Wesley, 1996.

13 Rakel D: Integrative Medicine, ed. 2. Philadelphia, Saunders, 2007.

14 Thabrew H, de Sylva S, Romans SE: Evaluating childhood adversity. Adv Psychosom Med 2012;32:35-57.

15 McEwen BS: Physiology and neurobiology of stress and adaptation: central role of the brain. Physiol Rev 2007;87:873-904.

16 Danese A, McEwen BS: Adverse childhood experiences, allostasis, allostatic load and agerelated disease. Physiol Behav 2012;106:2939.

17 Novack DH, Cameron O, Epel E, Ader R, Waldstein SR, Levenstein S, Antoni MH, Wainer AR: Psychosomatic medicine: the scientific foundation of the biopsychosocial model. Acad Psychiatry 2007;31:388-401.
18 Theorell T: Evaluating life events and chronic stressors in relation to health. Adv Psychosom Med 2012;32:58-71.

19 Fink G (ed): Stress Concept and Cognition, Emotion, and Behaviour. San Diego, Elsevier, 2016.

20 Nemeroff CB: Paradise lost: the neurobiological and clinical consequences of child abuse and neglect. Neuron 2016;89:892-909.

21 Grippo AJ, Scotti MA: Stress and neuroinflammation. Mod Trends Pharmacopsychiatry 2013;28:20-32.

22 Nemeroff CB, Goldschmidt-Clermont PJ: Heartache and heartbreak - the link between depression and cardiovascular disease. Nat Rev Cardiol 2012;9:526-539.

23 Schöttker B, Saum KU, Jansen EH, Holleczek $\mathrm{B}$, Brenner H: Associations of metabolic, inflammatory and oxidative stress markers with total morbidity and multi-morbidity in a large cohort of older German adults. Age Ageing 2016:45:127-135

24 Fava GA, Guidi J, Semprini F, Tomba E, Sonino N: Clinical assessment of allostatic load and clinimetric criteria. Psychother Psychosom 2010;79:280-284

25 Offidani E, Ruini C: Psychobiological correlates of allostatic overload in a healthy population. Brain Behav Immun 2012;26:284-291.

26 Offidani E, Rafanelli C, Gostoli S, Marchetti G, Roncuzzi R: Allostatic overload in patients with atrial fibrillation. Int J Cardiol 2013;165: 375-376.

27 Tomba E, Offidani E: A clinimetric evaluation of allostatic overload in the general population. Psychother Psychosom 2012;81:378379.

28 Guidi J, Offidani E, Rafanelli C, Roncuzzi R, Sonino N, Fava GA: The assessment of allostatic overload in patients with congestive heart failure by clinimetric criteria. Stress Health 2016;32:63-69.

29 McEwen BS, Bowles NP, Gray JD, Hill MN, Hunter RG, Karatsoreos IN, Nasca C: Mechanisms of stress in the brain. Nat Neurosci 2015;18:1353-1363.

30 McEwen BS, Gianaros PJ: Stress- and allostasis-induced brain plasticity. Annu Rev Med 2011;62:431-445.

31 Mokdad AH, Marks JS, Stroup DF, Gerberding JL: Actual causes of death in the United States, 2000. JAMA 2004;291:1238-1245.
32 Agirbasli M, Tanrikulu AM, Berenson GS: Metabolic syndrome: bridging the gap from childhood to adulthood. Cardiovasc Ther 2016;34:30-36

33 Emmen MJ, Peters E, Elving LD, Bredie SJH, Wollersheim H, Bleijenberg G, Schippers GM: A brief behavioral feedback intervention in hospital outpatients with a high cardiovascular risk. Patient Educ Couns 2006;60:3240.

34 Steptoe A, Wardle J: Cognitive predictors of health behavior in contrasting regions of Europe. Br J Clin Psychol 1992;31:485-502.

35 Gianaros PJ, Manuck SB: Neurobiological pathways linking socioeconomic position and health. Psychosom Med 2011;72:450-461.

36 Roy R: Social Support, Health and Illness. A Complicated Relationship. Toronto, University of Toronto Press, 2011.

37 Pressman SD, Cohen S: Does positive affect influence health? Psychol Bull 2005;131:925971

38 Ryff CD: Psychological well-being revisited: advances in the science and practice of eudaimonia. Psychother Psychosom 2014;83:1028.

39 Fava GA, Bech P: The concept of euthymia Psychother Psychosom 2016;85:1-5.

40 Cole SW: Human social genomics. PLoS Genet 2014;10:e1004601.

41 Currier MB, Nemeroff CB: Depression as a risk factor for cancer. Annu Rev Med 2014;65: 203-221.

42 Frederickson BL, Grewen KM, Algoes SB, Firestine AM, Arevalo JM, Ma J, Cole SW Psychological well-being and the human conserved transcriptional response to adversity. PLoS One 2015;10:e0121839.

43 Chida Y, Steptoe A, Powell LH: Religiosity/ spirituality and mortality. Psychother Psychosom 2009;78:81-90.

44 Morandi A, Narayanan Nambi AN (eds): An Integrated View of Health and Well-being. Dordrecht, Springer, 2013.

45 Cosci F: Assessment of personality in psychosomatic medicine: current concepts. Adv Psychosom Med 2012;32:133-159.

46 Friedman M, Rosenman RH: Type A Behavior and Your Heart. New York, Knopf, 1974.

47 Sirri L, Fava GA, Guidi J, Porcelli P, Rafanelli C, Bellomo A, Grandi S, Grassi L, Pasquini P, Picardi A, Quartesan R, Rigatelli M, Sonino $\mathrm{N}$ : Type A behavior: a reappraisal of its characteristics in cardiovascular disease. Int J Clin Pract 2012;66:854-861. 
48 De Vries AM, Forni V, Voellinger R, Stiefel F: Alexithymia in cancer patients: review of the literature. Psychother Psychosom 2012;81: 79-86.

49 Lumley MA, Neely LC, Burger AJ: The assessment of alexithymia in medical settings: implications for understanding and treating health problems. J Pers Assess 2007;89:230246.

50 Porcelli P, Bagby RM, Taylor GJ, De Carne M, Leandro G, Todarello O: Alexithymia as predictor of treatment outcome in patients with functional gastrointestinal disorders. Psychosom Med 2003;65:911-918.

51 Honkalampi K, Lehto SM, Koivumaa-Honkanen H, Hintikka J, Niskanen L, ValkonenKorhonen M, Viinamäki H: Alexithymia and tissue inflammation. Psychother Psychosom 2011;80:359-364.

52 Cloninger CR: A systematic method for clinical description and classification of personality variants. A proposal. Arch Gen Psychiatry 1987;44:573-588.

53 De Gucht V, Heiser W: Alexithymia and somatisation: quantitative review of the literature. J Psychosom Res 2003;54:425-434.

54 Fava M, Littman A, Halperin P: Neuroendocrine correlates of the type A behavior pattern. Int J Psychiatry Med 1987;17:289-307.

55 Engel GL: The need for a new medical model: a challenge for biomedicine. Science 1977; 196:129-136.

56 Levenstein S: Stress and peptic ulcer: life beyond helicobacter. BMJ 1999;316:538-541.

57 Waeldin S, Vogt D, Linden M, Hellhammer $\mathrm{DH}$ : Frequency of perceived post-stress symptoms in inpatients, outpatients and healthy controls. Psychother Psychosom 2016;85:36-44.

58 Katon WJ, Walker EA: Medically unexplained symptoms in primary care. J Clin Psychiatry 1998;59:15-21.

59 Hahn SR, Thompson KS, Wills TA, Stern V, Budner NS: The difficult doctor-patient relationship. J Clin Epidemiol 1994;47:647-657.

60 Sonino N, Guidi J, Fava GA: Psychological aspects of endocrine disease. J R Coll Physicians Edinb 2015;45:55-59.

61 Fava GA, Sonino N, Wise TN (eds): The Psychosomatic Assessment. Basel, Karger, 2012.

62 Keifenheim KE, Teufel M, Ip J, Speiser N, Leehr EJ, Zipfel S, Herrmann-Werner A: Teaching history taking to medical students. BMC Med Edu 2015;15:159.

63 Engel GL: A unified concept of health and disease. Perspect Biol Med 1960;3:459-485.

64 Hinkle LH: Human ecology and psychosomatic medicine. Psychosom Med 1967;29: 391-395.

65 Levin BW, Browner CH: The social production of health. Soc Sci Med 2005;61:745-750

66 Tinetti ME, Fried T: The end of the disease era. Am J Med 2004;116:179-185

67 Feinstein AR: The Jones criteria and the challenge of clinimetrics. Circulation 1982;66:1-5.
68 Bech P: Clinimetric dilemmas in outcome scales for mental disorders. Psychother Psychosom 2016;85:323-326.

69 Fava GA, Tomba E, Sonino N: Clinimetrics: the science of clinical measurements. Int J Clin Pract 2012;66:11-15.

70 Tomba E, Bech P: Clinimetrics and clinical psychometrics. Psychother Psychosom 2012; 81:333-340

71 Cosci CF, Svicher A, Bech P: The Family Assessment Device. A clinimetric analysis. Psychother Psychosom 2016;85:241-243.

72 Piolanti A, Offidani E, Guidi J, Gostoli S, Fava GA, Sonino N: Use of the PsychoSocial Index (PSI), a sensitive tool in research and practice. Psychother Psychosom 2016;85:337-345.

73 Grassi L, Berardi MA, Ruffilli F, Meggiolaro E, Andritsch E, Sirgo A, Caruso R, Juan Linares E, Bellé M, Massarenti S, Nanni MG; IOR-IRST Psycho-Oncology and UniFE Psychiatry Co-Authors: Role of psychosocial variables on chemotherapy-induced nausea and vomiting and health-related quality of life among cancer patients: a European study. Psychother Psychosom 2015;84:339-347.

74 Evers AW, Gieler U, Hasenbring MI, van Middendorp H: Incorporating biopsychosocial characteristics into personalized healthcare: a clinical approach. Psychother Psychosom 2014;83:148-157.

75 Derogatis LR, Lipman RS, Covi L: SCL-90: an outpatient psychiatric rating scale - preliminary report. Psychopharmacol Bull 1973;9: 13-28.

76 Snaith RP, Zigmond AS: The hospital anxiety and depression scale. Br Med J (Clin Res Ed) 1986;292:344

77 Kellner R: A symptom questionnaire. J Clin Psychiatry 1987;48:268-274.

78 Bech P: Clinical Psychometrics. Oxford, Wily-Blackwell, 2012.

79 Bech P: Measurement of psychological distress and well-being. Psychother Psychosom 1990;54:77-89.

80 Rodriguez-Urrutia A, Eiroa-Orosa FJ, Accarino A, Malagelada C, Azpiroz F: Incongruence between clinicians' assessments and selfreport functioning is related to psychopathology among patients diagnosed with gastrointestinal disorders. Psychother Psychosom 2016;85:244-245.

81 Topp CW, Østergaard SD, Søndergaard S, Bech P: The WHO-5 Well-Being Index: a systematic review of the literature. Psychother Psychosom 2015;84:167-176.

82 Bottomley A, Jones D, Claassens L: Patientreported outcomes: assessment and current perspectives of the guidelines of the Food and Drug Administration and the reflection paper of the European Medicine Agency. Eur J Cancer 2009; 45:347-353.

83 Clancy C, Collins FS: Patient-Center Outcomes Research Institute: the intersection of science and health care. Sci Transl Med 2010; $3: 37$.
84 Concato J, Feinstein AR: Asking patients what they like: overlooked attributes of patient satisfaction with primary care. Am J Med 1997;102:399-406.

85 Mechanic D, Volkart EH: Illness behavior and medical diagnoses. J Health Hum Behav 1960; 1:86-94.

86 Mechanic D: Sociological dimensions of illness behavior. Soc Sci Med 1995;41:12071216.

87 Sirri L, Fava GA, Sonino: The unifying concept of illness behavior. Psychother Psychosom 2013;82:74-81.

88 Cosci F, Fava GA: The clinical inadequacy of the DSM-5 classification of somatic symptom and related disorders: an alternative trans-diagnostic model. CNS Spectr 2016;21:310-317.

89 American Psychiatric Association: Diagnostic and Statistical Manual of Mental Disorders, ed 5. Washington, American Psychiatric Association, 2013.

90 Fava GA, Grandi S: Differential diagnosis of hypochondriacal fears and beliefs. Psychother Psychosom 1991;55:114-119.

91 Noyes R, Carney CP, Langbehn DR: Specific phobia of illness: search for a new subtype. J Anxiety Disord 2004;18:531-545.

92 Porcelli P, Bellomo A, Quartesan R, Altamura M, Iuso S, Ciannameo I, Piselli M, Elisei S: Psychosocial functioning in consultation-liaison psychiatry patients: influence of psychosomatic syndromes, psychopathology and somatization. Psychother Psychosom 2009;78: 352-358.

93 Galeazzi GM, Ferrari S, Mackinnon A, Rigatelli M: Interrater reliability, prevalence, and relation to ICD-10 diagnoses of the Diagnostic Criteria for Psychosomatic Research in consultation-liaison psychiatry patients. Psychosomatics 2004;45:386-393.

94 Kellner R: Psychosomatic syndromes, somatization and somatoform disorders. Psychother Psychosom 1994;61:4-24.

95 Mayer EA, Tillisch K: The brain-gut axis in abdominal pain syndromes. Annu Rev Med 2011;62:381-396.

96 Mayer EA, labus JS, Tillisch K, Cole SW, Baldi P: Toward a systems view of IBS. Nat Rev Gastroenterol Hepatol 2015;12:592-605.

97 Ly HG, Ceccarini J, Weltens N, Bormans G, Van Laere K, Tack J, Van Oudenhove L: Increased cerebral cannabinoid-1 receptor availability is a stable feature of functional dyspepsia: a $\left[{ }^{18} \mathrm{~F}\right] \mathrm{MK}-9470$ PET study. Psychother Psychosom 2015;84:149-158.

98 Engel GL: Conversion symptoms; in MacBryde CM, Blacklow RS (eds): Signs and Symptoms, Applied Pathological Physiology and Clinical Interpretation. Philadelphia, Lippincott, 1970, pp 650-668.

99 American Psychiatric Association: Diagnostic and Statistical Manual of Mental Disorders, ed 4. Washington, American Psychiatric Association, 1994. 
100 Porcelli P, Fava GA, Rafanelli C, Bellomo A, Grandi S, Grassi L, Pasquini P, Picardi A, Quartesan R, Rigatelli M, Sonino N: Anniversary reactions in medical patients. J Nerv Ment Dis 2012;200:603-606.

101 Grassi L, Sabato S, Rossi E, Biancosino B, Marmai L: Use of the diagnostic criteria for psychosomatic research in oncology. Psychother Psychosom 2005;74:100-107.

102 Grandi S, Sirri L, Tossani E, Fava GA: Psychological characterization of demoralization in the setting of heart transplantation. J Clin Psychiatry 2011;72:648-654.

103 Pilowsky I: Abnormal Illness Behaviour. Chichester, Wiley, 1997.

104 Frank JD: Persuasion and Healing. Baltimore, Johns Hopkins University Press, 1961.

105 Schmale AH, Engel GL: The giving up-given up complex illustrated on film. Arch Gen Psychiatry 1967;17:133-145.

106 Tecuta L, Tomba E, Grandi S, Fava GA: Demoralization: a systematic review on its clinical characterization. Psychol Med 2015;45: 673-691.

107 Sweeney DR, Tinling DC, Schmale AH: Differentiation of the 'giving-up' affects - helplessness and hopelessness. Arch Gen Psychiatry 1970;23:378-382.

108 Benedetti F: The Patient's Brain. The Neuroscience behind the Doctor-Patient Relationship. Oxford, Oxford University Press, 2011.

109 Snaith RP, Taylor CM: Irritability. Br J Psychiatry $1985 ; 147: 127-136$.

110 Fava GA: Irritable mood and physical illness. Stress Med 1987;3:293-299.

111 Miller TQ, Smith TW, Turner CW, Guijarro ML, Hallet AJ: A meta-analytic review of research on hostility and physical health. Psychol Bull 1996;119:322-348.

112 Chida Y, Steptoe A: The association of anger and hostility with future coronary heart disease: a meta-analytic review of prospective evidence. J Am Coll Cardiology 2009;53: 936-946.

113 Lemogne C, Nabi H, Zins M, Cordier S, Ducimetière $\mathrm{P}$, Goldberg M, Consoli SM: Hostility may explain the association between depressive mood and mortality: evidence from the French GAZEL cohort study. Psychother Psychosom 2010;79:164-171.

114 Klabbers G, Bosma H, van den Akker M, Kempen GI, van Eijk JT: Cognitive hostility predicts all-cause mortality irrespective of behavioural risk at late middle and older age. Eur J Public Health 2013;23:701-705.

115 Sonino N, Navarrini C, Ruini C, Ottolini F, Paoletta A, Fallo F, Boscaro M, Fava GA: Persistent psychological distress in patients treated for endocrine disease. Psychother Psychosom 2004;73:78-83.

116 Sartorius N, Holt RIG, Maj M (eds): Comorbidity of Mental and Physical Disorders. Basel, Karger, 2015.

117 Cosci F, Fava GA, Sonino N: Mood and anxiety disorders as early manifestations of medical illness. Psychother Psychosom 2015;84:22-29.
118 Fava GA, Sonino N: Depression associated with medical illness. CNS Drugs 1996;5: 175-189.

119 Mitchell Aj, Vaze A, Rao S: Clinical diagnosis of depression in primary care: a metaanalysis. Lancet 2009;374:609-619.

120 Rafanelli C, Sirri L, Grandi S, Fava GA: Is depression the wrong treatment target for improving outcome in coronary artery disease? Psychother Psychosom 2013;82:285-291.

121 Sonino N, Fava GA, Raffi AR, Boscaro M, Fallo F: Clinical correlates of major depression in Cushing's disease. Psychopathology 1998;31:302-306.

122 Sonino N, Zielezny M, Fava GA, Fallo F, Boscaro M: Risk factors and long-term outcome in pituitary-dependent Cushing's disease. J Clin Endocrinol Metab 1996;81: 2647-2652.

123 Katon WJ: Clinical and health services relationships between major depression, depressive symptoms and general medical illness. Biol Psychiatry 2003;54:216-226.

124 Di Matteo MR, Lepper HS, Croghan TW: Depression is a risk factor for noncompliance with medical treatment. Arch Intern Med 2000;160:2101-2107.

125 Lipowski ZJ: Physical illness and psychopathology. Int J Psychiatry Med 1974;5:483497.

126 Schulz R, Drayer RA, Rollman BL: Depression as a risk factor for non-suicide mortality in the elderly. Biol Psychiatry 2002;52: 205-225.

127 Roy-Byrne PP, Davidson KW, Kessler RC, Asmundson GJG, Goodwin RD, Kubzansky L, Lydiard RB, Massic MJ, Katon WJ, Laden SK, Stein MB: Anxiety disorders and comorbid medical illness. Gen Hosp Psychiatry 2008;30:208-225.

128 Fava GA, Porcelli P, Rafanelli C, Mangelli L, Grandi S: The spectrum of anxiety disorders in the medically ill. J Clin Psychiatry 2010; 71:910-914.

129 Niles AN, Dour HJ, Stanton AL, Roy-Byrne $\mathrm{PP}$, Stein MB, Sullivan G, Sherbourne CD, Rose RD, Craske MG: Anxiety and depressive symptoms and medical illness among adults with anxiety disorders. J Psychosom Res 2015;78:109-115.

130 Hanel G, Henningsen P, Herzog W, Sauer N, Schaefert R, Szecsenyi J, Löwe B: Depression, anxiety, and somatoform disorders: vague or distinct categories in primary care? Results from a large cross-sectional study. J Psychosom Res 2009;67:189-197.

131 Fava GA, Guidi J, Porcelli P, Rafanelli C, Bellomo A, Grandi S, Grassi L, Mangelli L, Pasquini P, Picardi A, Quartesan R, Rigatelli M, Sonino N: A cluster analysis-derived classification of psychological distress and illness behavior in the medically ill. Psychol Med 2012;42:401-407.

132 Semprini F, Fava GA, Sonino N: The spectrum of adjustment disorders: too broad to be clinically helpful. CNS Spectr 2010;15: 382-388.
133 Emmelkamp PM, Bouman TK, Scholing A: Anxiety Disorders. Chichester, Wiley, 1993.

134 Kroenke K, Mangelsdorff D: Common symptoms in ambulatory care. Am J Med 1989;86:262-268.

135 Konnopka A, Schaefert R, Heinrich S, Kaufman C, Luppa M, Herzog, Konig HH: Economics of medical unexplained symptoms. Psychother Psychosom 2012;81:265275.

136 Croicu C, Chwastiak L, Katon W: Approach to the patient with multiple somatic symptoms. Med Clin North Am 2014;98:10791095.

137 Sonino N, Fava GA: Improving the concept of recovery in endocrine disease by consideration of psychosocial issues. J Clin Endocrinol Metab 2012;97:2614-2616.

138 Kornfeld DS: Consultation-liaison psychiatry: contributions to medical practice. Am J Psychiatry 2012;159:1964-1972.

139 Fava GA, Cosci F, Offidani E, Guidi J: Behavioral toxicity revisited: iatrogenic comorbidity in psychiatric evaluation and treatment. J Clin Psychopharmacol, in press.

140 Djoussé L, Driver JA, Graziano JM: Relation between modifiable lifestyle factors and lifetime risk of heart failure. JAMA 2009;302: 394-400.

141 Forman JP, Stampfer MJ, Curhan GC: Diet and lifestyle risk factors associated with incident hypertension in women. JAMA 2009; 302:401-411.

142 Tomba E: Assessment of lifestyle in relation to health. Adv Psychosom Med 2012;32:72-96.

143 Stone NJ: Focus on lifestyle change and the metabolic syndrome. Endocrinol Metab Clin North Am 2004;33:493-508.

144 Shonkoff JP, Boyce WT, McEwen BS: Neuroscience, molecular biology and the childhood roots of health disparities. JAMA 2009; 301:2252-2259.

145 Abramson J: Overdosed America. New York, HarperCollins, 2004.

146 Leventhal H, Weinman J, Leventhal EA, Phillips LA: Health psychology: the search for pathways between behavior and health. Annu Rev Psychol 2008;59:477-505.

147 Smith TW, Williams PG: Behavioral medicine and clinical health psychology; in Lambert MJ (ed): Bergin and Garfield's Handbook of Psychotherapy and Behavior Change, ed 6. Hoboken, Wiley, 2013, pp 690-734.

148 Gerger H, Hlavica M, Gaab J, Munder T, Barth J: Does it matter who provides psychological interventions for medically unexplained symptoms? A meta-analysis. Psychother Psychosom 2015;84:217-226.

149 Rickels K (ed): Non-specific factors in drug therapy. Springfield, Charles C. Thomas, 1968.

150 Gliedman CH, Nash EH, Huber SD, Stone AR, Frank JD: Reduction of symptoms by pharmacologically inert substances and by short-term psychotherapy. AMA Arch Neurol Psychiatry 1958;79:345-351. 
151 Zilcha-Mano S, Roose SP, Barber JP, Rutherford BR: Therapeutic alliance in antidepressant treatment: cause or effect of symptomatic levels? Psychother Psychosom 2015; 84:177-182.

152 Walach H: Placebo effects in complementary and alternative medicine: the self-healing response; In Colloca L, Flaten MA, Meissner K (eds): Placebo and Pain. London, Academic Press, 2013, pp 189-202.

153 Schedlowski M, Enck P, Rief, Bingel U: Neuro-bio-behavioral mechanisms of placebo and nocebo responses: implications for clinical trials and clinical practice. Pharmacol Rev 2015;67:697-730.

154 Egbert LD, Battit GE, Welch CE, Bartlett MK: Reduction of postoperative pain by encouragement and instruction of patients. $\mathrm{N}$ Engl J Med 1964;270:825-827.

155 Uhlenhuth EN, Rickels K, Fisher S, Park LC, Lipman RS, Mock J: Drug, doctor's verbal attitude and clinic setting in the symptomatic response to pharmacotherapy. Psychopharmacologia 1966;9:392-418.

156 Enck P, Bingel U, Schedlowski M, Rief W: The placebo response in medicine: minimize, maximize or personalize? Nature Rev Drug Discov 2013;12:191-204.

157 Kaupp JW, Rapaport-Hubschman N, Spiegel D: Psychosocial treatments; in Levenson JL (ed): Textbook of Psychosomatic Medicine. Washington, American Psychiatric Press, 2005, pp 923-956.

158 Abbass A, Kisely S, Kroenke K: Short-term psychodynamic psychotherapy for somatic disorders. Psychother Psychosom 2009;78: 265-274.

159 Hartmannn M, Bazner E, Wild B, Eisler I, Herzog W: Effects of interventions involving the family in the treatment of adult patients with chronic physical disease. Psychother Psychosom 2010;79:136-148.

160 Cosci F, Fava GA: Psychotherapeutic Interventions; in Carvalho AF, Manning JS, McIntyre RS (eds): Mental Disorders in Primary Care. A Guide to their Evaluation and Treatment. London, Oxford University Press, in press.

161 Rozanski A, Blumenthal JA, Kaplan J: Impact of psychological factors on the pathogenesis of cardiovascular disease and implications for therapy. Circulation 1999;99: 2192-2217.

162 Janssen V, Gucht VD, Dusseldorp E, Maes S: Lifestyle modification programmes for patients with coronary heart disease: a systematic review and meta-analysis of randomized controlled trials. Eur J Prev Cardiol 2013;20: 620-640.

163 Dindo L, Marchman J, Gindes H, Fiedorowicz JG: A brief behavioral intervention targeting mental health risk factors for vascular disease. Psychother Psychosom 2015;84: $183-185$.

164 Gulliksson M, Burell G, Vessby B, Lundin L, Toss H, Svärdsudd K: Randomized controlled trial of cognitive behavioral therapy vs standard treatment to prevent recurrent cardiovascular events in patients with coronary heart disease: Secondary Prevention in Uppsala Primary Health Care project (SUPRIM). Arch Intern Med 2011;171:134-140.

165 Rankin P, Morton DP, Diehl H, Gobble J, Morey P, Chang E: Effectiveness of a volunteer-delivered lifestyle modification program for reducing cardiovascular disease risk factors. Am J Cardiol 2012;109:82-86.

166 Laird KT, Tanner-Smith EE, Russell AC, Hollon SD, Walker LS: Short-term and longterm efficacy of psychological therapies for irritable bowel syndrome. Clin Gastroenterol Hepatol 2016;14:937-947.e4.

167 Farver-Vestergaard I, Jacobsen D, Zachariae $\mathrm{R}$ : Efficacy of psychosocial interventions on psychological and physical health outcomes in chronic obstructive pulmonary disease: a systematic review and meta-analysis. Psychother Psychosom 2015;84:37-50.

168 Thibault RT, Lishfitz M, Birbaumer N, Raz A: Neurofeedback, self-regulation and brain imaging. Psychother Psychosom 2015;84: 193-207.

169 Turk DC, Swanson KS, Tunks ER: Psychological approaches in the treatment of chronic pain patients. Can J Psychiatry 2008; 53:213-223.

170 Dale R, Stacey B: Multimodal treatment of chronic pain. Med Clin North Am 2016;100: 55-64.

171 Diabetes Prevention Program Research Group: Long-term effects of lifestyle intervention or metformin on diabetes development and microvascular complications over 15-year follow-up. Lancet Diabetes Endocrinol 2015;3:866-879.

172 Tovote KA, Schroevers MJ, Snippe E, Sanderman R, Links TP, Emmelkamp PM, Fleer $\mathrm{J}$ : Long-term effects of individual mindfulness-based cognitive therapy and cognitive behavior therapy for depressive symptoms in patients with diabetes: a randomized trial. Psychother Psychosom 2015;84:186-187.

173 Scott-Sheldon LA, Kalichman SC, Carey MP, Fielder RI: Stress management interventions for HIV+ adults. Health Psychol 2008;27:129-139.

174 Crepaz N, Tungol-Ashmon MV, Higa DH, Vosburgh VV, Mullins MM, Barham T, Adegbite A, DeLuca JB, Sipe TA, White CM, Baack BN, Lyles CM: A systematic review of interventions for reducing HIV risk behaviors among people living with HIV in the United States, 1988-2012. AIDS 2014;28: 633-656.

175 Andersen BL, Yang HC, Farrar WB, Golden-Krentz DM, Emery CF, Thornton LM, Young DC, Carson WE: Psychologic intervention improves survival for breast cancer patients. Cancer 2008;113:3450-3458.

176 Minton O, Jo F, Jane M: The role of behavioural modification and exercise in the management of cancer-related fatigues to reduce its impact during and after cancer treatment. Acta Oncol 2015;54:581-586.
177 Julião M, Nunes B, Barbosa A: Dignity therapy and its effect on the survival of terminally ill Portuguese patients. Psychother Psychosom 2015;84:57-58.

178 Hou RJ, Wong SYS, Yip BHB, Hung ATF, Lo HHM, Chan PHS, Lo CSL, Kwok TCY, Tang WK, Mak WWS, Mercer SW, Ma SH: The effects of mindfulness-based stress reduction program on the mental health of family caregivers. Psychother Psychosom 2014;83: 45-53.

179 Fava GA: Well-Being Therapy. Treatment Manual and Clinical Applications. Basel, Karger, 2016.

180 Fava GA: Well-Being Therapy: current indications and emerging perspectives. Psychother Psychosom 2016;85:136-145.

181 Hasler G: Well-being. An important concept for psychotherapy and psychiatric neuroscience. Psychother Psychosom 2016;85:255261.

182 Sirri L, Ricci Garotti MG, Grandi S, Tossani E: Adolescents' hypochondriacal fears and beliefs. J Psychosom Res 2015;79:259264.

183 Rafanelli C, Bonomo M, Gostoli S: Is binge drinking in adolescence related to specific impairments in well-being? Psychother Psychosom 2016;85:366-367.

184 Sonino N, Fava GA: Rehabilitation in endocrine patients: a novel psychosomatic approach. Psychother Psychosom 2007;76: 319-324.

185 Mojtabai R: Clinician-identified depression in community settings: concordance with structured-interview diagnoses. Psychother Psychosom 2013;82:161-169.

186 Ilyas S, Moncrieff J: Trends in prescriptions and costs of drugs for mental disorders in England, 1998-2010. Br J Psychiatry 2012; 200:393-398.

187 Cloos JM, Bocquet V, Rolland-Portal I, Koch P, Chouinard G: Hypnotics and triazolobenzodiazepines - best predictors of high-dose benzodiazepine use: results from the Luxembourg National Health Insurance Registry. Psychother Psychosom 2015;84:273283.

188 Zito JM: High-dose benzodiazepine use among long-term users: when will we ever learn? Psychother Psychosom 2015;84:259261.

189 Starcevic V, Brakoulias V, Viswasam K, Berle $\mathrm{D}$ : Inconsistent portrayal of medication dependence, withdrawal and discontinuation symptoms in treatment guidelines for anxiety disorders. Psychother Psychosom 2015;84:379-380.

190 Chouinard G, Chouinard VA: New classification of selective serotonin reuptake inhibitor withdrawal. Psychother Psychosom 2015;84:3-71

191 Fava GA, Gatti A, Belaise C, Guidi J, Offidani E: Withdrawal symptoms after selective serotonin reuptake inhibitor discontinuation. Psychother Psychosom 2015;84:6371. 
192 Fava GA, Tomba E, Tossani E: Innovative trends in the design of clinical trials in psychopharmacology and psychotherapy. Progr Neuropsychopharmacol Biol Psychiatry 2013;40:306-311.

193 Fava GA, Cosci F, Tomba E: Iatrogenic comorbidity in mental health. Psychother Psychosom 2015;84(suppl 1):22.

194 Ferrando SJ, Levenson JL, Owen JA (eds): Clinical Manual of Psychopharmacology in the Medically Ill. Washington, American Psychiatric Publishing, 2010.

195 Cosci F, Guidi J, Balon R, Fava GA: Clinical methodology matters in epidemiology: not all benzodiazepines are the same. Psychother Psychosom 2015;84:262-264.

196 Fava GA, Guidi J, Rafanelli C, Sonino N: The clinical inadequacy of evidence-based medicine and the need for a conceptual framework based on clinical judgment. Psychother Psychosom 2015;84:1-3.

197 Fava GA: Rational use of antidepressant drugs. Psychother Psychosom 2014;83:197204.

198 Taylor D, Meader N, Bird V, Pilling S, Creed F, Goldberg D; Pharmacology subgroup of the National Institute for Health and Clinical Excellence Guideline Development Group for Depression in Chronic Physical Health Problems: Pharmacological interventions for people with depression and chronic physical health problems: systematic review and meta-analyses of safety and efficacy. Br J Psychiatry 2011;198:179-188.

199 Iovieno N, Tedeschini E, Ameral VE, Rigatelli M, Papakostas GI: Antidepressants for major depressive disorder in patients with co-morbid axis-III disorder. Int Clin Psychopharmacol 2011;26:69-74.

200 Jackson JL, de Zee K, Berbano E: Can treating depression improve disease outcomes? Ann Intern Med 2004;140:1054-1056.

201 Rackley S, Bostwick JM: Depression in medically ill patients. Psychiatr Clin North Am 2012;35:231-247.

202 Carvalho AF, Sharma MS, Brunoni AR, Vieta E, Fava GA: The safety, tolerability and risks associated with the use of newer generation antidepressant drugs: a critical review of the literature. Psychother Psychosom 2016;85:270-288.
203 Tinetti ME, Fried TR, Boyd CM: Designing health care for the most common chronic condition - multimorbidity. JAMA 2012; 307:2493-2494.

204 Suls J, Green PA, Davidson KW: A biobehavioral framework to address the emerging challenge of multimorbidity. Psychosom Med 2016;78:281-289.

205 Linden M: Psychosomatic inpatient rehabilitation: the German model. Psychother Psychosom 2014;83:205-212.

206 Zipfel S, Herzog W, Kruse J, Henningsen P: Psychosomatic medicine in Germany: more timely than ever. Psychother Psychosom 2016;85:262-269.

207 Yoshiuci K: How can psychosomatic physicians contribute to behavioral medicine? Biopsychosoc Med 2016;10:8.

208 Nakao M, Takeuchi T, Fricchione G: Definition of psychosomatic medicine and the applicability of DSM-IV-TR to outpatients visiting a Japanese psychosomatic clinic. Psychother Psychosom 2014;83:120-121.

209 Yuan Y, Wu A, Jiang W: Psychosomatic medicine in China. Psychother Psychosom 2015;84:59-60.

210 Lipowski ZJ: Psychiatric consultation. Am J Psychiatry 1977; 134:523-528.

211 Wood R, Wand AP: The effectiveness of consultation-liaison psychiatry in the general hospital setting. J Psychosom Res 2014; 76:175-192.

212 Shaw RJ, Demaso DR (eds): Textbook of Pediatric Psychosomatic Medicine. Washington, American Psychiatric Publishing, 2010.

213 Wood R, Wand APF: The effectiveness of consultation-liaison psychiatry in the general hospital setting. J Psychosom Res 2014; 76:175-192.

214 Sledge WH, Gueorguieva R, Desan P, Bozzo JE, Dorset J, Lee HB: Multidisciplinary proactive psychiatric consultation service: impact on length of stay for medical inpatients. Psychother Psychosom 2015;84:208-216.

215 Dantzer R: Somatization: a psychoneuroimmune perspective. Psychoneuroendocrinology 2005;30:947-952.
216 Thayer JF, Brosschot JF: Psychosomatics and psychopathology. Psychoneuroendocrinology 2005;30:1050-1058.

217 Schiffer RB, Klein RF, Sider RC: The Medical Evaluation of Psychiatric Patients. New York, Plenum, 1988.

218 Isaac ML, Larson EB: Medical conditions with neuropsychiatric manifestations. Med Clin North Am 2014;98:1193-1208.

219 Sonino N, Peruzzi P: A psychoneuroendocrinology service. Psychother Psychosom 2009;78:346-351.

220 The Remission Clinic Task Force: The Remission Clinic approach to halt the progression of kidney disease. J Nephrol 2011;24: 274-281.

221 Fung-Kee-Fung M, Kennedy EB, Biagi J, Colgan T, D'Souza D, Elit LM, Hunter A, Irish J, McLeod R, Rosen B: The optimal organization of gynecologic oncology services: a systematic review. Curr Oncol 2015; 22:e282-e293.

222 Betteridge N, Boehncke WH, Bundy C, Gossec L, Gratacós J, Augustin M: Promoting patient-centred care in psoriatic arthritis: a multidisciplinary European perspective on improving the patient experience. J Eur Acad Dermatol Venereol 2016;30:576-585.

223 Layard R, Clark DM: Why more psychological therapy would cost nothing. Front Psychol 2015;6:1713.

224 Hart JT: Clinical and economic consequences of patients as producers. J Public Health Med 1995;17:383-386.

225 Joosten EA, DeFuentes-Merillas L, de Weert GH, Sensky T, van der Staak CP, de Jong CA: Systematic review of the effects of shared decision-making on patient satisfaction, treatment adherence and health status. Psychother Psychosom 2008;77:219-226.

226 Bodenheimer T, Lorig K, Holman H, Grumbach K: Patient self-management of chronic disease in primary care. JAMA 2002;288: 2469-2475.

227 Kroenke K: Psychological medicine. BMJ 2002;324:1536-1537.

228 Ioannidis JPA: Evidence-based medicine has been hijacked: a report to David Sackett. J Clin Epidemiol 2016;73:82-86.

229 Horwitz RI, Cullen MR, Abell J, Christian JB: (De)personalized medicine. Science 2013;339:1155-1156. 